\title{
Prevalence and Pattern of Musculoskeletal Pain Among Undergraduates from a Nigerian University
}

\author{
Ayanniyi O., ${ }^{1}$ Udofia U.I. ${ }^{2}$ \\ ${ }^{1}$ Department of Physiotherapy, College of Medicine, University of Ibadan/University College Hospital (UCH), \\ Ibadan, Nigeria \\ ${ }^{2}$ Department of Physiotherapy, College of Medicine, University of Ibadan/University College Hospital (UCH), \\ Ibadan, Nigeria
}

Correspondence

Dr. Olusola Ayanniyi, Department of Physiotherapy, College of Medicine, University of Ibadan/University College Hospital (UCH), Ibadan, Nigeria・E-mail: drayanniyi@gmail.com

\section{SUMMARY}

Musculoskeletal pain (MSP) is a common cause of severe long-term pain and physical disability affecting millions of people around the world. This study investigated the prevalence and pattern of MSP among Nigerian undergraduates.

A cross-sectional survey of undergraduates from three purposively selected halls of residence of the University of Ibadan, Nigeria was conducted over a period of 10 weeks using a standardized Nordic questionnaire and a pre-tested questionnaire. Data obtained were analysed using descriptive and inferential statistics.

Of the 600 questionnaires administered $532(88.67 \%)$ were fully completed and found admissible for analysis. The mean age of the respondents was $23.4 \pm 2.34$ years (range 17-34)]. Lifetime and point prevalence of MSP was 54.5\% and 51.7\% respectively. Lifetime occurrence of MSP was highest in the low back (55.1\%) followed by the neck (53.8\%). Duration of pain resulting from MSP was 1-7 days and it prevented normal daily activities in $20.7 \%$ of respondents. There was a significant association between lifetime prevalence of MSP and each of age group $(p=0.001)$, sex $(p=0.046)$, lecture duration $(0.001)$, and extracurricular activity $(p=0.001)$. Self-medication $(55.6 \%)$ was the most common health practice for MSP.

Musculoskeletal pain is a common disorder among Nigerian undergraduates. The low back and the neck were the most affected. MSP was perceived to be caused by prolonged poor postures assumed during lectures, and it predisposes to limitation of daily activities. Preventive strategies to reduce MSP among Nigerian undergraduates are necessary.

KEY WORDS: Musculoskeletal pain, university undergraduates, prevalence, pattern, Nigeria

\section{INTRODUCTION}

Musculoskeletal pain (MSP) is a common cause of severe long-term pain and physical disability (De Inocencio, 2004) affecting millions of people around the world (Woolf and Pfleger, 2003). MSP is known to be work-related with variations in the proportion of affectation among different occupational groups (Ayanniyi et al, 2016). University undergraduates, who are predominantly occupied with studying, are arguably a distinct "occupational" group. Emerging studies indicate that university students are a high-risk group for MSP due to their prolonged hours of school work and reading(Smith and Leggat, 2007; Ayanniyi et al, 2010). Undergraduate populations have been evaluated for specific MSPs and have been determined to 
have a greater risk of developing MSP (Nyland and Grimmer, 2003; Rising et al, 2005; Ayanniyi et al, 2010) The school environment is thought to be a very important setting for the development of MSP (Rising et al, 2005; Smith and Leggat, 2007; Ayanniyi et al, 2010), as about $30 \%$ of school time is spent in prolonged sitting position (Nurul et al 2009).

In addition to school-related activities, high activity levels with consequent injuries have been implicated in the development of MSP among adolescents and young adults (De Inocencio, 2004). MSP in early ages is of public health importance, as literature reveals that occurrence of MSP in childhood and adolescence subsequently transitioned into adulthood (Brattberg, 2004; Hestbaek et al, 2006; Kamaleri et al, 2009). Considering the upsurge in MSP prevalence in adolescents and young adults, there is a need to conduct research to better understand the precipitating and perpetuating factors of MSP in order to be able to proffer effective solutions for its prevention and management (Hill and Keating, 2009; Kamper et al, 2016). At present in Nigeria, unlike in the Western world such as the United Kingdom and the United States of America, the problem of MSP in adolescents and young adults is yet to receive sufficient attention among researchers, despite emerging studies that implicate MSP among children and adolescents as a likely precursor of chronic pain in adulthood (Hestbaek et al, 2006; Jones et al, 2007). This study, therefore, investigated the prevalence and pattern of MSP among Nigerian university undergraduates.

\section{MATERIAL AND METHODS}

\section{Participants}

Participants for this study were undergraduates of the University of Ibadan who were resident in the university campus.

\section{Methods}

This was a cross-sectional survey study on the prevalence and pattern of musculoskeletal pain among undergraduates of the University of Ibadan.

\section{Procedure}

Ethical approval for this study was obtained from the University of Ibadan/University College Hospital (UI/UCH) Research Ethics Committee. Also, the approval of the administrative authorities of the selected halls of residence was obtained prior to commencement of the study. Signed informed consent of the respondents was also obtained. The respondents were recruited from three purposively selected halls of residence in the University based on their peculiar characteristics. The halls were: Alexander Brown Hall, Queen Idia Hall, and Nnamdi Azikiwe Hall. Queen Idia (female) and Nnamdi Azikiwe (male) Halls were selected because they have a higher population of students than other halls of residence, while Alexander Brown Hall (male and female) was selected in order to include clinical medical students in the study. Participation in this study was delimited only to consented undergraduates of the University of Ibadan who were resident in the selected halls of residence.

The population of undergraduates in the selected halls was 2,901. A total sample of 514 participants was calculated for the study using the formula by Yamane (1967) and the level of precision for the study was set at 0.04 . However, to allow for refusal to participate and incomplete or invalid returned questionnaire, 600 questionnaires were distributed.

\section{Data Collection Procedure}

Data were collected at the close of the day when the students could be met at the hall of residence between the hours of 16.00 - 20. $00 \mathrm{hr}$. Every even-numbered room was sampled and consenting undergraduate residents in the enumerated rooms were recruited into the study. A letter of instruction explaining the purpose and nature of the study was attached to the questionnaire. This also contained adequate instructions on how to fill the questionnaire.

The Standardized Nordic Questionnaire (SNQ) (Kuorinka et al, 1987) and a previously validated questionnaire by Ayanniyi et al (2010) were used as the survey instruments. The two-sectioned SNQ was used to obtain information on MSP. The first section comprises close-ended questions that seek information on the areas of the body affected by musculoskeletal problems. Completion of the SNQ is aided by a body diagram which indicates nine sites, namely neck, shoulders, upper back, elbows, low back, wrist/hands, hip/thighs, knees and ankles/feet. The second section of the questionnaire relates to the neck, the shoulder, and the lower back. The psychometric properties and clinical usability of the SNQ are well demonstrated in the literature (Kuorinka et al, 1987; Azuan et al, 2010). Similarly, the SNQ has been found usable in previous studies among Nigerians (Ayanniyi et al, 2010; Akinpelu et al, 2010). The second questionnaire by Ayanniyi et al 
(2010) was used to obtain information on sociodemographic characteristics, present and past history of MSP, perceived causes of MSP and care-seeking behaviour of undergraduates with MSP. The questionnaire was tested for clarity and comprehensibility in a pilot study among 20 students selected from two faculties (Agriculture and Forestry; and the Social Sciences ) of the same university. All areas of concern to the assessors were corrected and incorporated into the final questionnaire for the study.

The questionnaires were distributed to the respondents by hand and were self-administered. Completed questionnaires were collected immediately or after a week, where immediate collection was not possible. Data collection was completed within a 10 -week time frame, in the year 2012 .

The data obtained were stratified for in-depth analysis by level of study and distribution by faculty. The term "level of study" refers to the class of the respondents based on the year of admission into the university. Fresh students (newly admitted students) were referred to as 100 level students. Prevalence rates were also assessed as part of the study. Point prevalence was defined as the proportion of the surveyed participants that had MSP at the time of contact during the study. Period prevalence was the proportion of the surveyed population that had MSP at some time during a given period (e.g. 12-month prevalence and 7-days prevalence) up to the period of the study. Lifetime prevalence (LTP) is the proportion of the surveyed population that have experienced MSP at some point in their life up to the time of the survey (Rothman, 2012).

\section{Data analysis}

Descriptive statistics of frequency, percentage, and mean and standard deviation were used to summarize data. Inferential statistics of Chi-square was used to test the association between MSP and each of the sociodemographic and school-related variables. Data were analysed using the Statistical Package for Social Sciences (SPSS) for Windows, version 16. Alpha level was set at $\mathrm{p}<0.05$.

\section{RESULTS}

A total of 532 undergraduates out of 600 who fully completed and returned their questionnaires were included in this study. This yielded a response rate of $88.7 \%$ while 68 copies of the distributed questionnaires were not included in the study due to non-completion or non-return by the respondents. The mean age of the respondents was $23.4 \pm 2.54$ years. The highest population of the respondents $(191(35.9 \%))$ fell within the age range of 21 to 25 years. Table 1 shows the socio-demographic characteristics of the respondents.

Table 1. Socio-demographic characteristics of the respondents

\begin{tabular}{|c|c|c|}
\hline Variables & Frequency & Percentage \\
\hline \multicolumn{3}{|l|}{ Sex } \\
\hline Male & 302 & 56.8 \\
\hline Female & 230 & 43.2 \\
\hline \multicolumn{3}{|l|}{ Age } \\
\hline $15-20$ years & 175 & 33.0 \\
\hline 21-25 years & 191 & 35.9 \\
\hline $26-30$ years & 164 & 30.8 \\
\hline 30 and above & 2 & 0.4 \\
\hline \multicolumn{3}{|l|}{ Level of study } \\
\hline 100 & 79 & 14.8 \\
\hline 200 & 96 & 14.3 \\
\hline 300 & 95 & 17.9 \\
\hline 400 & 130 & 24.4 \\
\hline 500 & 93 & 17.5 \\
\hline 600 & 59 & 11.1 \\
\hline \multicolumn{3}{|l|}{ Faculty } \\
\hline Faculty of Science & 45 & 8.5 \\
\hline Faculty of Agriculture & 25 & 4.7 \\
\hline Faculty of Education & 36 & 6.8 \\
\hline Faculty of Technology & 38 & 7.1 \\
\hline Faculty of Arts & 27 & 5.1 \\
\hline Faculty of Social Sciences & 40 & 7.5 \\
\hline Faculty of Pharmacy & 34 & 6.4 \\
\hline Faculty of Veterinary Medicine & 34 & 6.4 \\
\hline Faculty of Public Health & 22 & 4.1 \\
\hline Faculty of Law & 20 & 3.8 \\
\hline Faculty of Basic Medical Sciences & 18 & 3.4 \\
\hline Faculty of Dentistry & 78 & 14.7 \\
\hline Faculty of Clinical Sciences & 115 & 21.6 \\
\hline \multicolumn{3}{|l|}{ Religion } \\
\hline Christianity & 469 & 88.2 \\
\hline Islam & 63 & 11.8 \\
\hline Others & 0 & 0.0 \\
\hline
\end{tabular}

Lifetime and point prevalence of MSP among the respondents in this study were $54.5 \%$ and $51.7 \%$ respectively (table 2). The anatomical pattern of MSP by gender and level of study is presented in table 3. The most common pain site was the neck $(50.4 \%)$, followed by the low back $(38.7 \%)$. The result of the 12 -month prevalence of MSP by body region indicates that the low back $(55.1 \%)$ 
followed by the neck $(53.8 \%)$ were the worst hit anatomical sites. There was no gender bias in the pattern of distribution of 12-month prevalence of MSP by body site. The 7-days prevalence of MSP indicates that hip/thigh (27.4\%) followed by upper back pain $(27.3 \%)$ were the most affected (table 4). Frequency distribution of perceived causes of musculoskeletal pain is presented in table 4 . Posture assumed during lectures was the most reported $(23.0 \%)$ as the cause of the respondents' MSP experience. Pain duration was for a total time of 1-7 days and prevented normal daily activities in $20.7 \%$ of the respondents (table 5).

Table 6 shows the 12-month and 7-days pattern of MSP in different body regions based on faculties. Students from the Faculty of Agriculture and Forestry had the highest rates of MSP affecting the neck $(88.0 \%)$ and the low back (72.0\%). The correlates of lifetime prevalence of MSP with socio-demographic and school-related activities are presented in table 7 . There was significant association between lifetime prevalence of MSP and each of age ( $\mathrm{p}=$ $0.001)$, sex $(p=0.046)$, lecture duration (0.001), and extracurricular activity $(\mathrm{p}=0.001)$ but not with level of study $(p=0.479)$ or religion $(p=0.209)$. Furthermore, there was a significant association between lifetime prevalence of MSP and each of self-medication $(p=0.001)$ and utilization of physiotherapy $(p=0.001)$.

Table 2. Lifetime and point prevalence of musculoskeletal pain among the respondents $(\mathrm{N}=565)$

\begin{tabular}{|c|c|c|c|c|c|c|c|c|c|c|}
\hline \multirow[t]{2}{*}{ Variables } & \multicolumn{2}{|c|}{ All students } & \multicolumn{2}{|c|}{$15-20 y r s$} & \multicolumn{2}{|c|}{$21-25 y r s$} & \multicolumn{2}{|c|}{$26-30 y r s$} & \multicolumn{2}{|c|}{$31 \mathrm{yrs}$ and above } \\
\hline & $\mathrm{n}$ & $\%$ & $\mathrm{n}$ & $\%$ & $\mathrm{n}$ & $\%$ & $\mathrm{n}$ & $\%$ & $\mathrm{n}$ & $\%$ \\
\hline Lifetime prevalence & 290 & 54.5 & 84 & 29.0 & 69 & 23.8 & 135 & 46.6 & 2 & 0.7 \\
\hline Point prevalence & 275 & 51.7 & 74 & 29.4 & 74 & 29.4 & 126 & 45.8 & 1 & 0.4 \\
\hline
\end{tabular}

KEY: N/n $=$ Number,

$\%=$ Percentage, $\quad$ Yrs $=$ Age in years

Table 3. Anatomical pattern of musculoskeletal pain by gender, level of study and period prevalence rates

\begin{tabular}{|c|c|c|c|c|c|c|c|c|c|}
\hline \multicolumn{10}{|c|}{ 12-months prevalence } \\
\hline \multirow[t]{2}{*}{ Sex } & Neck & Shoulder & Elbow & W rist & Upper back & Low back & Hips & Knee & Ankle \\
\hline & $\%$ & $\%$ & $\%$ & $\%$ & $\%$ & $\%$ & $\%$ & $\%$ & $\%$ \\
\hline Male & 59.3 & 55.3 & 6.0 & 26.5 & 46.4 & 60.0 & 44.4 & 14.2 & 12.6 \\
\hline Female & 46.5 & 46.3 & 10.8 & 38.2 & 30.0 & 47.8 & 27.0 & 27.8 & 23.5 \\
\hline \multirow[t]{2}{*}{ Level of study } & Neck & Shoulder & Elbow & W rist & Upper back & Low back & Hips & Knee & Ankle \\
\hline & $\%$ & $\%$ & $\%$ & $\%$ & $\%$ & $\%$ & $\%$ & $\%$ & $\%$ \\
\hline 100 & 53.2 & 49.1 & 6.3 & 21.5 & 44.3 & 51.9 & 36.7 & 17.7 & 19.0 \\
\hline 200 & 65.8 & 52.6 & 7.9 & 32.9 & 53.9 & 60.5 & 48.7 & 18.4 & 15.8 \\
\hline 300 & 61.1 & 50.5 & 7.4 & 21.1 & 48.4 & 56.8 & 51.6 & 18.9 & 17.9 \\
\hline 400 & 53.1 & 42.3 & 6.9 & 31.5 & 34.6 & 57.7 & 40.0 & 17.7 & 10.8 \\
\hline 500 & 50.5 & 49.5 & 11.8 & 41.9 & 31.2 & 51.6 & 41.5 & 30.1 & 23.7 \\
\hline 600 & 33.9 & 32.2 & 8.5 & 44.1 & 22.0 & 49.2 & 15.3 & 16.9 & 20.3 \\
\hline \multicolumn{10}{|c|}{ 7-days prevalence } \\
\hline \multirow[t]{2}{*}{ Sex } & Neck & Shoulder & Elbow & Wrist & Upper back & Low back & Hips & Knee & Ankle \\
\hline & $\%$ & $\%$ & $\%$ & $\%$ & $\%$ & $\%$ & $\%$ & $\%$ & $\%$ \\
\hline Male & 12.6 & 39.1 & 0.7 & 4.6 & 39.4 & 15.6 & 39.4 & 5.0 & 5.0 \\
\hline Female & 15.3 & 10.0 & 2.6 & 7.4 & 11.3 & 19.6 & 11.7 & 8.7 & 8.7 \\
\hline \multirow[t]{2}{*}{ Level of study } & Neck & Shoulder & Elbow & W rist & Upper back & Low back & Hips & Knee & Ankle \\
\hline & $\%$ & $\%$ & $\%$ & $\%$ & $\%$ & $\%$ & $\%$ & $\%$ & $\%$ \\
\hline 100 & 12.7 & 31.6 & 0.0 & 3.8 & 29.1 & 11.4 & 31.6 & 6.3 & 12.7 \\
\hline 200 & 14.5 & 40.8 & 1.3 & 6.6 & 40.8 & 18.4 & 40.8 & 10.5 & 7.9 \\
\hline 300 & 14.7 & 29.5 & 3.2 & 8.4 & 32.6 & 12.6 & 34.7 & 7.4 & 3.2 \\
\hline 400 & 11.5 & 28.5 & 2.3 & 3.1 & 27.7 & 19.2 & 31.5 & 4.6 & 3.8 \\
\hline 500 & 14.0 & 11.8 & 1.1 & 6.5 & 17.2 & 16.1 & 8.6 & 6.5 & 5.4 \\
\hline 600 & 16.9 & 15.3 & 0.0 & 8.4 & 13.6 & 28.8 & 13.6 & 5.1 & 10.2 \\
\hline
\end{tabular}


Table 4. Frequency distribution on perceived causes of musculoskeletal pain

\begin{tabular}{lcc}
\hline Variable & Frequency & Percentage \\
\hline Seats without back support & 110 & 20.7 \\
used during lecture & & \\
Prolonged reading & 34 & 6.4 \\
Using the computer & 22 & 4.1 \\
Posture assumed during & 122 & 23.0 \\
lectures & & \\
Posture assumed during & 72 & 13.5 \\
practical/ clinical hours & & \\
Prolonged sitting & 88 & 16.5 \\
Prolonged standing & 103 & 19.4 \\
Other & 37 & 7.0 \\
No response & 54 & 10.2 \\
\hline
\end{tabular}

The association between point prevalence of MSP and each socio-demographic and school-related activity is presented in table 8 . There is significant association between point prevalence of MSP and each of age ( $\mathrm{p}=$ $0.001)$, sex $(p=0.001)$, and lecture duration $(0.001)$, but not with level of study $(\mathrm{p}=0.060)$, religion $(\mathrm{p}=0.087)$ and extracurricular activity $(\mathrm{p}=0.347)$. Similarly, there was significant association between point prevalence of MSP and each of self-medication $(p=0.001)$ and drug use $(\mathrm{p}=0.024)$ but not with the utilization of physiotherapy ( $p$ $=0.539)$. Self-medication $(55.6 \%)$ was the most common health practice for MSP. This was followed by respondents who sought medical intervention $(34.2 \%)$, those who received physiotherapy $(15.2 \%)$, while $7.1 \%$ of the respondents used alternate home preparations medicine to manage their MSP.
Table 5. Duration of musculoskeletal pain and limitation of daily activities in the body region for 12 months prior to study

\begin{tabular}{|c|c|c|c|}
\hline $\begin{array}{l}\text { Body } \\
\text { region }\end{array}$ & Days & $\begin{array}{l}\text { Experience pain } \\
\text { Frequency (\%) }\end{array}$ & $\begin{array}{l}\text { Limitation of } \\
\text { Work } \\
\text { Frequency (\%) }\end{array}$ \\
\hline \multirow{6}{*}{$\begin{array}{l}\text { Low } \\
\text { back }\end{array}$} & 0 days & $73(13.7)$ & $241(45.3)$ \\
\hline & $1-7$ days & $206(38.7)$ & $131(24.6)$ \\
\hline & 8-30 days & $107(20.1)$ & $2(0.4)$ \\
\hline & $\begin{array}{l}\text { More than } 30 \text { days but } \\
\text { not everyday }\end{array}$ & $23(4.3)$ & $21(3.9)$ \\
\hline & Everyday & $4(0.8)$ & $1(0.2)$ \\
\hline & No response & $119(22.4)$ & $136(25.6)$ \\
\hline \multirow[t]{6}{*}{ Neck } & 0 days & $220(41.4)$ & $249(46.8)$ \\
\hline & 1-7 days & $268(50.4)$ & $110(20.7)$ \\
\hline & 8-30 days & $13(2.4)$ & $2(0.4)$ \\
\hline & $\begin{array}{l}\text { More than } 30 \text { days but } \\
\text { not everyday }\end{array}$ & $20(3.8)$ & $2(0.4)$ \\
\hline & Everyday & $10(1.9)$ & $9(1.7)$ \\
\hline & No response & $1(0.2)$ & $160(30.1)$ \\
\hline \multirow[t]{5}{*}{ Shoulder } & 0 days & $239(44.9)$ & $249(46.8)$ \\
\hline & 1-7 days & $69(13.0)$ & $68(12.8)$ \\
\hline & 8-30 days & $3(0.6)$ & $4(0.8)$ \\
\hline & $\begin{array}{l}\text { More than } 30 \text { days but } \\
\text { not everyday }\end{array}$ & $3(0.6)$ & $1(0.2)$ \\
\hline & Everyday & $218(41.0)$ & $210(39.5)$ \\
\hline
\end{tabular}

Table 6. 12-month and 7-days pattern of MSP in different body region based on faculties

\begin{tabular}{|c|c|c|c|c|c|c|c|c|c|}
\hline Faculties & $\begin{array}{l}\text { Neck } \\
\% \\
\end{array}$ & $\begin{array}{l}\text { Shoulder } \\
\%\end{array}$ & $\begin{array}{l}\text { Elbow } \\
\%\end{array}$ & $\begin{array}{l}\text { Wrist } \\
\%\end{array}$ & $\begin{array}{l}\text { Upper back } \\
\%\end{array}$ & $\begin{array}{l}\text { Low back } \\
\%\end{array}$ & $\begin{array}{l}\text { Hips } \\
\% \\
\end{array}$ & $\begin{array}{l}\text { Knee } \\
\%\end{array}$ & $\begin{array}{l}\text { Ankle } \\
\%\end{array}$ \\
\hline \multicolumn{10}{|l|}{ 12-month } \\
\hline Science & 60.0 & 48.9 & 8.9 & 20.0 & 44.4 & 57.8 & 55.3 & 11.1 & 20.0 \\
\hline Agric. & 88.0 & 60.2 & 8.0 & 24.0 & 68.0 & 72.0 & 56.0 & 16.0 & 16.0 \\
\hline Education & 58.3 & 52.8 & 0.0 & 36.1 & 44.4 & 66.7 & 41.7 & 13.9 & 13.9 \\
\hline Technology & 50.0 & 40.1 & 10.5 & 36.8 & 28.9 & 52.6 & 42.1 & 26.3 & 21.1 \\
\hline Art & 74.1 & 63.0 & 14.8 & 40.7 & 66.7 & 74.1 & 55.6 & 7.4 & 22.2 \\
\hline Social Sciences & 60.0 & 55.0 & 7.5 & 25.0 & 50.0 & 55.0 & 45.0 & 27.5 & 12.5 \\
\hline Pharmacy & 61.8 & 61.8 & 5.9 & 5.9 & 61.8 & 67.6 & 55.9 & 20.6 & 5.9 \\
\hline Vet. & 55.9 & 55.9 & 2.9 & 11.8 & 47.1 & 61.8 & 41.2 & 14.7 & 11.8 \\
\hline Public Health & 81.8 & 59.1 & 4.5 & 9.1 & 68.2 & 54.5 & 68.2 & 13.6 & 13.6 \\
\hline Law & 35.0 & 30.0 & 5.0 & 35.0 & 25.0 & 40.0 & 25.0 & 20.0 & 10.0 \\
\hline Basic Medical & 61.1 & 44.4 & 0.0 & 33.3 & 55.6 & 50.0 & 38.9 & 27.8 & 22.2 \\
\hline \multicolumn{10}{|l|}{ Sciences } \\
\hline Dentistry & 42.3 & 34.6 & 6.4 & 46.2 & 12.8 & 50.0 & 11.5 & 21.8 & 19.2 \\
\hline Clinical Sciences & 38.3 & 35.7 & 13.9 & 41.7 & 26.1 & 44.3 & 21.7 & 25.2 & 21.7 \\
\hline
\end{tabular}


Musculoskeletal Pain Among University Undergraduates

Key: $\quad$ MSP $=$ Musculoskeletal Pain,

$\%=$ Percentage

Table 7. Association between lifetime prevalence of MSP and each of age, sex, level of study, religion, lecture duration, and extracurricular activity

\begin{tabular}{|c|c|c|c|c|}
\hline \multirow[t]{2}{*}{ Variable } & \multicolumn{2}{|c|}{ Lifetime } & \multirow[t]{2}{*}{$x^{2}$} & \multirow[t]{2}{*}{$\mathrm{P}$} \\
\hline & Yes n $(\%)$ & No n $(\%)$ & & \\
\hline \multicolumn{5}{|l|}{ Age } \\
\hline $15-20$ years & $84(29.0)$ & $91(37.6)$ & 81.834 & $0.001 *$ \\
\hline $21-25$ years & $69(23.8)$ & $122(50.4)$ & & \\
\hline $26-30$ years & $135(46.6)$ & $29(12.0)$ & & \\
\hline 31 and above & $2(0.7)$ & $0(0.0)$ & & \\
\hline \multicolumn{5}{|l|}{ Sex } \\
\hline Male & $176(60.7)$ & $126(52.1)$ & 3.997 & $0.046 *$ \\
\hline Female & $114(39.3)$ & $116(47.4)$ & & \\
\hline \multicolumn{5}{|l|}{ Level of Study } \\
\hline 100 & $45(15.5)$ & $34(14.0)$ & 4.509 & 0.479 \\
\hline 200 & $43(14.8)$ & $33(13.6)$ & & \\
\hline 300 & $56(19.3)$ & $39(16.1)$ & & \\
\hline 400 & $74(25.5)$ & $56(23.1)$ & & \\
\hline 500 & $44(15.2)$ & $49(20.2)$ & & \\
\hline 600 & $28(9.7)$ & $31(12.8)$ & & \\
\hline \multicolumn{5}{|l|}{ Religion } \\
\hline Christianity & $251(82.2)$ & $218(90.1)$ & 1.575 & 0.209 \\
\hline Islam & $39(13.4)$ & $24(9.9)$ & & \\
\hline \multicolumn{5}{|l|}{ Lecture } \\
\hline \multicolumn{5}{|l|}{ Duration (hrs) } \\
\hline 1 to $<10$ & $30(10.3)$ & $34(12.0)$ & 82.344 & $0.001 *$ \\
\hline 10 to $<20$ & $41(14.1)$ & $89(36.8)$ & & \\
\hline 20 to $<30$ & $63(21.7)$ & $73(30.2)$ & & \\
\hline 30 to $<40$ & $34(11.7)$ & $21(8.2)$ & & \\
\hline 40 to $<50$ & $116(40.0)$ & $23(9.5)$ & & \\
\hline 50 and above & $6(2.1)$ & $2(0.8)$ & & \\
\hline Extracurricular & $73(25.3)$ & $215(74.7)$ & 11.098 & $0.001 *$ \\
\hline \multicolumn{5}{|l|}{ Activity } \\
\hline \multicolumn{5}{|l|}{ Care-seeking } \\
\hline \multicolumn{5}{|l|}{ Behaviour } \\
\hline Self-medication & $212(82.5)$ & $45(17.5)$ & 47.855 & $0.001 *$ \\
\hline Drugs & $111(44.0)$ & $141(56.0)$ & 0.023 & 0.879 \\
\hline Physiotherapy & $34(13.5)$ & $217(86.5)$ & 16.307 & $0.001 *$ \\
\hline Other & $9(39.1)$ & $14(60.9)$ & 0.263 & 0.608 \\
\hline
\end{tabular}

Table 8. Association between Point prevalence of MSP and each of age, sex, level of study, religion, lecture duration, and extracurricular activity

\begin{tabular}{|c|c|c|c|c|}
\hline \multirow[t]{2}{*}{ Variable } & \multicolumn{2}{|c|}{ Lifetime } & \multirow[t]{2}{*}{$x^{2}$} & \multirow[t]{2}{*}{$\mathrm{P}$} \\
\hline & Yes n $(\%)$ & No n $(\%)$ & & \\
\hline \multicolumn{5}{|l|}{ Age } \\
\hline $15-20$ years & $74(26.9)$ & $101(39.5)$ & 60.066 & $0.001 *$ \\
\hline 21-25 years & $74(26.9)$ & $116(45.3)$ & & \\
\hline 26-30 years & $126(45.8)$ & $38(14.8)$ & & \\
\hline 31 and above & $1(0.4)$ & $1(0.1)$ & & \\
\hline \multicolumn{5}{|l|}{ Sex } \\
\hline Male & $174(67.3)$ & $127(49.6)$ & 10.081 & $0.001 *$ \\
\hline Female & $101(36.7)$ & $129(50.4)$ & & \\
\hline \multicolumn{5}{|l|}{ Level of Study } \\
\hline 100 & $40(14.5)$ & $39(15.2)$ & 10.615 & 0.060 \\
\hline 200 & $41(14.9)$ & $35(13.7)$ & & \\
\hline 300 & $57(20.7)$ & $38(14.8)$ & & \\
\hline 400 & $74(26.9)$ & $56(21.9)$ & & \\
\hline 500 & $37(13.5)$ & $56(21.9)$ & & \\
\hline 600 & $26(9.5)$ & $32(12.5)$ & & \\
\hline \multicolumn{5}{|l|}{ Religion } \\
\hline Christianity & $236(85.8)$ & $232(90.6)$ & 2.930 & 0.087 \\
\hline Islam & $39(14.2)$ & $24(9.6)$ & & \\
\hline \multicolumn{5}{|l|}{ Lecture } \\
\hline \multicolumn{5}{|l|}{ Duration (hrs) } \\
\hline 1 to $<10$ & $24(8.7)$ & $40(15.6)$ & 93.398 & $0.001 *$ \\
\hline 10 to $<20$ & $54(19.6)$ & $76(29.7)$ & & \\
\hline 20 to $<30$ & $42(15.3)$ & $94(36.7)$ & & \\
\hline 30 to $<40$ & $34(12.4)$ & $20(7.8)$ & & \\
\hline 40 to $<50$ & $116(42.2)$ & $23(9.0)$ & & \\
\hline 50 and above & $5(1.8)$ & $3(1.2)$ & & \\
\hline Extracurricular & $91(33.2)$ & $183(66.8)$ & 0.886 & 0.347 \\
\hline \multicolumn{5}{|l|}{ Activity } \\
\hline \multicolumn{5}{|l|}{ Care-seeking } \\
\hline \multicolumn{5}{|l|}{ Behaviour } \\
\hline Self-medication & $196(80.7)$ & $47(19.3)$ & 30.719 & $0.001 *$ \\
\hline Drugs & $94(39.2)$ & $114(60.8)$ & 5.082 & $0.024 *$ \\
\hline Physiotherapy & $50(20.9)$ & $189(79.1)$ & 0.377 & 0.377 \\
\hline Other & $22(61.1)$ & $14(38.9)$ & 7.887 & $0.006^{*}$ \\
\hline
\end{tabular}




\section{DISCUSSION}

This study investigated the prevalence and pattern of MSP among Nigerian undergraduates. The majority of the undergraduates in this study were between 21-25 years of age. It is usual for undergraduates all over the world to fall within the age bracket of $18-22$ years, though some could be considerably older or younger (Egbochuku and Akpan, 2006). The age bracket of respondents in this study is similar to that reported by Stanford University (2011) which put the average age of American undergraduates at between 18-20 years. The data for Nigeria is less precise, however, most of the undergraduates in Nigerian universities are in their adolescent years (Egbochuku and Akpan, 2006).

There is a high lifetime $(54.5 \%)$ and point $(51.7 \%)$ prevalence of MSP among Nigerian undergraduates with higher preponderance among male students. The higher preponderance of male students suffering from MSP as found in this study may be a reflection of such variables associated with higher involvement of male students in high-level physical activities than their female counterparts or other variables outside the present study. However, this finding is at variance with previous findings among a similar population in a similar setting with respect to the prevalence of neck pain (Ayanniyi et al 2010). The pattern of lifetime MSP by body site affected indicates that the low back $(55.1 \%)$, followed by the neck $(53.8 \%)$ were the most affected anatomical parts, while the least affected site was the elbow (8.1\%). Nyland and Grimmer (2003), in a study among physiotherapy students at the University of South Australia found a lifetime prevalence of $69 \%$ for LBP while Hayes et al (2009) reported an overall of $57.9 \%$ for 12 months prevalence of LBP among Dental Hygiene students in Australia. The higher prevalence of MSP affecting the low back in the present study is consistent with previous studies in the general population (Jorgensen et al, 1991; Kilbom et al, 1996). The common occupational related back pain among workers is attributed to prolonged and static (motionless) muscle contraction and the repetitive use of muscles (Kilbom et al, 1996).

In the present study, a higher prevalence of neck pain was found among undergraduates than those previously reported by Ayanniyi et al (2010), who found a lifetime prevalence of $34.9 \%$ among Nigerian undergraduates; and Lorusso et al (2010) who reported $16 \%$ lifetime prevalence of neck pain among Italian X-ray technology students. However, this is consistent with the finding by Gamperiene and Stigum (1999). Point prevalence of MSP shows that the hip/thigh (27.4\%) followed by the upper back (27.3\%) were the most affected body parts. This is contrary to the finding by Harutunian et al (2011) with a higher prevalence of MSP in the upper back $(40.5 \%)$ among Dentistry postgraduate students compared with the present study.

Large proportions of students with MSP in this study were in the higher levels of study (200-400 level). This may imply that the higher the level in the university, the higher the risk of MSP. Vikat et al (2000), in a study exploring neck or shoulder pain and low-back pain (LBP) in Finnish adolescents found that students in higher academic classes had higher rates of MSP. This may imply that the higher levels of study in the university make more demand on the musculoskeletal system or that the higher levels are periods when accumulated non-symptomatic musculoskeletal disorders begin to manifest. However, many fresh students (100 level students) also reported experiencing an increase in MSP. This is consistent with the finding by Uchakin et al (2001) who suggest that academic stress in first-year students causes an alteration in the health status of freshmen, thereby making them susceptible to ill health.

Students from the Faculty of Agriculture and Forestry in this study had the highest lifetime prevalence of MSP with the neck $(88.0 \%)$ and the low back $(72.0 \%)$ as the most affected body parts. The high lifetime prevalence of low back among the Agriculture and Forestry students in this study is higher compared to an earlier report by Eva et al (2007) who found a $15.7 \%$ prevalence of MSP among farm workers high school students in Starr Country, Texas. The prevalence of neck pain and LBP among the Agriculture and Forestry students in this study may be attributed to the lack or limited availability and use of ergonomically-designed farm implements and mechanized farming in the University of Ibadan.

The findings on predisposing factors for MSP in this study implicated the use of seats without back support. A larger proportion of the students who used seats without back support during lectures indicated that the posture assumed during lectures was a perceived cause of MSP than those who used seats with back support during lectures. Previous studies have implicated the use of seats without back support as a risk factor for MSP (Schroder, 1997; Ayanniyi et al, 2010). Most of the students in this study perceived their MSP to be multifactorial in origin. This is consistent with the finding of Siivola et al (2004). The posture assumed during lectures was perceived as a cause of MSP (22.9\%) in this study. Previous studies also 
implicated awkward postures usually assumed by most workers as the cause of MSP, especially LBP and pain in other parts of the body (Pope et al, 2002). Prolonged standing was also indicated as a perceived cause of MSP in this study. This may be connected to some types of school work which can only be performed standing, such as laboratory work and cadaver dissection among students in the Faculty of Basic Medical Sciences. A significant association between lifetime prevalence of MSP and each of age, sex and lecture duration was found among the respondents in this study. However, religion and extracurricular activity did not significantly influence the prevalence of MSP among the respondents. This is contrary to the findings by Ayanniyi et al (2010) with respect to MSP affecting the neck.

The normal daily activities of some of the respondents were limited by MSP for between one to seven days. This finding is in agreement with those of Rosecrance and Cook (1998) who reported that work-related MSP is a leading cause of lost time from work, with a resultant loss of productivity, significant human suffering and worker disability. The commonest health seeking behaviour to alleviate musculoskeletal pain among the respondents was self-medication $(55.6 \%)$. This is consistent with the previous finding among adolescents suffering from LBP where self-medication (27\%) was the predominant means of management (Ayanniyi et al, 2011). This may be due to unrestricted access to off-the-shelf analgesic drugs to manage musculoskeletal pain. It may also be a reflection of the perception of the respondents concerning their MSP as not being serious enough to warrant the attention of health care professionals. It is important to point out that there is a very close similarity in our findings with respect to point prevalence and seven days prevalence, therefore it could be assumed that point prevalence to some extent is already included in the findings with respect to seven days prevalence. Hence seven days prevalence may take precedence over point prevalence. Overall, it is amazing that over $50 \%$ of undergraduates in their twenties have MSP. Therefore, it is necessary that in-depth studies should be carried out to discover the reasons behind such occurrences.

\section{Limitations}

This study had a number of limitations. The questionnaires did not address the respondent's perspective as to whether their MSP actually worsened after starting their undergraduate programme. This is very important as their responses could have been compared with empirical research findings. Equally, the section of the questionnaire that addressed extracurricular activities was not sufficiently broken down into specific sports and activities to provide more insight into this aspect of campus life. Recall bias may also have affected the responses. This is not unexpected with a questionnaire survey. However, in order to minimize recall bias, the respondents were instructed to depend on their best memory recall. Also, the outcome of this study may not necessarily confirm the actual presence and severity of the underlying musculoskeletal disorders in view of the fact that the study was a self-reported cross-sectional survey. However, the high prevalence of MSP may point to the possibility of an underlying disorder. Caution should also be exercised in postulations on the mechanism responsible for MSP in terms of school and pain since there is no control study to verify such an assumption specifically.

\section{Further/future Research Focus}

A number of studies can be elicited from this work. It is important to know the perception of undergraduates about the specific burden their academic activities impose on them compared with other issues surrounding university education in Nigeria in particular. It could also be useful to compare findings between privately-owned institutions and government-owned institutions with respect to the problem of MSP among undergraduates.

\section{Implications of the Findings}

It can be inferred from this study that MSP is a common occurrence among undergraduates of the University of Ibadan. Therefore, there is a need for the university authorities to address the problem among the undergraduates by deliberately instituting holistic approaches that will encompass both preventive and effective management of the problem.

\section{CONCLUSION}

Musculoskeletal pain is a common disorder among Nigerian undergraduates with lifetime and point prevalence of $54.50 \%$ and $51.7 \%$ respectively. The low back followed by the neck are the most affected anatomical sites by MSP in undergraduates. MSP is perceived to be caused largely by prolonged poor postures assumed during lectures, and it limits daily activities. Age, sex, lecture duration, and 
extracurricular activity were significant correlates of occurrence of MSP. Preventive strategies to reduce MSP among Nigerian undergraduates are necessary.

\section{Declaration of interest}

The authors report no conflict of interest.

\section{Acknowledgement}

Special thanks go to all the students who participated in this study. We are also grateful to the authorities of the various halls of residence for their kind permission to conduct this study.

\section{REFERENCES}

Akinpelu AO, Odole AC, Odejide A. 2010. Prevalence and pattern of musculoskeletal pain in rural community in southwestern Nigeria. The Internet Journal of Epidemiology 8: 2.

Ayanniyi O, Mbada CE, Muolokwu CA. 2010. Neck pain occurrence and characteristics in Nigerian university undergraduates. TAF Preventive Medicine Bulletin 9: 167-174.

Ayanniyi O, Mbada CE, Iroko OP. 2011. Prevalence and profile of back pain in Nigerian adolescents. Medical Principles and Practice 20: 368 - 373.

Ayanniyi O, Nudamajo OS, Mbada CE. 2016. Pattern of workrelated musculoskeletal disorders among Nigerian hospital workers. Journal of Environmental and Occupational Science 5(1): $18-24$.

Azuan MK, Zailina H, Shamsul BMT, Asyiqin MAN, Azhar MNM, Aizat IS. 2010. Neck, upper back and lower back pain and associated risk factors among primary school children. Journal of Applied Sciences 10: 431-435.

Brattberg G. 2004. Do pain problems in young school children persist into early adulthood? A 13-year follow-up. European Journal of Pain 8(3): 187-199.

De Inocencio J. 2004. Epidemiology of musculoskeletal pain in primary care. Archives of Disorders in Children 89(5): 431-434.

Egbochuku EO, Akpan JJ. 2006. The effect of reciprocal peer counselling in the enhancement of self-concept among adolescents. Education 126(3): 504-511.

Eva MS, Sharon PC, Deborah JD, George LD, Keith DB, Susan RT. 2007. Severe back pain among farmworker high school students. Annual Epidemiological Study 17: 132-141.

Gamperiene M., Stigum H. 1999. Work related risk factors for musculoskeletal complaints in the spinning industry in Lithuania. Occupational Environmental Medicine 56(6): 411416.

Harutunian K., Gargallo-Albiol J., Figueiredo R., Gay-Escoda C. 2011. Ergonomics and musculoskeletal pain among postgraduate students and faculty members of the School of Dentistry of the University of Barcelona (Spain). A cross- sectional study. Medicina Oral Patologia Oral y Cirugia Bucal 16(3): e425 - 9.

Hayes M.J., Smith D.R., Cockrell D. 2009. Prevalence and correlates of musculoskeletal disorders among Australian dental hygiene students. International Journal of Dental Hygiene 7(3): 176-81.

Hestbaek L, Leboeuf-Yde C, Kyvik KO, Manniche C. 2006. The course of low back pain from adolescence to adulthood: Eightyear follow-up of 9600 twins. Spine 31(4): 468-472.

Hill J.J., Keating J.L. 2009. A systematic review of the incidence and prevalence of low back pain in children. Physical Therapy Reviews 14(4): 272-84. http://dx.doi.org/10.1179/108331 909X1248 8667116899.

Jones G.T., Silman A.J., Power C., Macfarlane G.J. 2007. Are common symptoms in childhood associated with chronic widespread body pain in adulthood? Results from the 1958 British Birth Cohort Study. Arthritis Rheumatology 56(5): 1669-75. http://dx.doi.org/10.1002/art.22587. PMid:17469161.

Jorgensen K., Jensen B.R., Kato M. 1991. Fatigue development in the lumbar paravertebral muscles of bricklayers during the working day. International Journal of Industrial Ergonomics 8(3): 237-245.

Kamaleri Y., Natvig B., Ihlebaek C.M., Benth J.S., Bruusgaard D. 2009. Change in the number of musculoskeletal pain sites: A 14-year prospective study. Pain 141(1-2): 25-30.

Kamper S.J., Henschke N., Hestbaek L., Dunn K.M., Williams C.M. 2016. Musculoskeletal pain in children and adolescents. Brazilian Journal of Physical Therapy http://dx.doi.org/10.1590/bjptrbf.2014.0149.

Kilbom A., Armstrong T., Buckle P. 1996. Musculoskeletal disorders: Work related risk factor and prevention. International Journal of Occupational Environment and Health 2(3): 239-246.

Kuorinka .I, Jonsson B., Kilbom A., Vinterberg H., BieringSorensen F., Anderson G., Jorgensen K. 1987. Standardised Nordic questionnaires for the analysis of musculoskeletal symptoms. Applied Ergonomics 18: 233-237.

Lorusso A., Bruno S., Abbate L.N. 2010. Musculoskeletal disorder among Italian X-ray technology students. BMC Research Notes 3(114). doi:10. 1186/1756 - 0500 - 3 -114.

Nurul A.M.A., Shamsul B.M.T., Mohd S.D., Mohamad A.M.N., Mohd R.B., Zailina H. 2009. Neck, shoulder, upper and lower back pain and associated risk factors among primary school children in Malaysia. Journal of Medical Safety 2: 37-47.

Nyland L.J., Grimmer K.A. 2003. Is undergraduate physiotherapy study a risk factor for low back pain? A prevalence study of LBP in physiotherapy students. BMC Musculoskeletal Disorder 4: 22. doi: 10.1186/1471-2474-4-22.

Pope M.H., Goh K.L., Magnusson M.L. 2002. Spine ergonomics. Annual Review of Biomedical Engineering 4: 49- 68.

Rising D.W., Bennett B.C., Hursh K., Plesh O. 2005. Reports of body pain in a dental student population. Journal of the American Dental Association 136(1): 81-86. 
Rosecrance J.C., Cook T.M. 1998. Upper extremity musculoskeletal disorders: Occupational association and a model for prevention. CEJOEM 4(3): 214-231.

Rothman K.J. 2012. Epidemiology: An Introduction $2^{\text {nd }}$ edition. Oxford: University Press, p. 53.

Schroder I. 1997. Variation of sitting posture and physical activity in different types of school furniture. Colegium $l$ Antropologium 21(2): 397-403.

Smith D.R., Leggat P.A. 2007. Back Pain in the young: A review of studies conducted among school children and university students. Current Pediatric Reviews 3: 69-77.

Siivola SM, Levoska S, Latvala K, Hoskio E, Vanharanta H, Keinanen-Kiukaanniemi S. 2004. Predictive factors for neck and shoulder pain: A longitudinal study in young adults. Spine 29(15): 1662-1669.

Stanford University Common Data Set 2011-2012. 2011; Retrieved online from: http://ucomm.stanford.edu/cds/ 2011.html Accessed 3 January 2016 at $08.00 \mathrm{pm}$.

Uchakin P.N., Tobin B., Cubbage M., Marshal G. Jr, Sams C. 2001. Immune responsiveness following academic stress in first-year medical students. Journal of Interferon Cytokine Research 21(9): 687-694.

Vikat A., Rimpela M., Salminen J.J., Rimpela A., Savolainen A., Virtanen S.M. 2000. Neck or shoulder pain and low back pain in Finnish adolescents. Scandinavian Journal of Public Health 28(3): 164-173.

Woolf A.D., Pfleger B. 2003. Burden of major musculoskeletal conditions. Bulletin of the World Health Organisation 81(9): 646- 656.

Yamane T. 1967. Statistics, An introductory analysis. 2nd edition. New York: Harper and Row, pp 807-886. 